
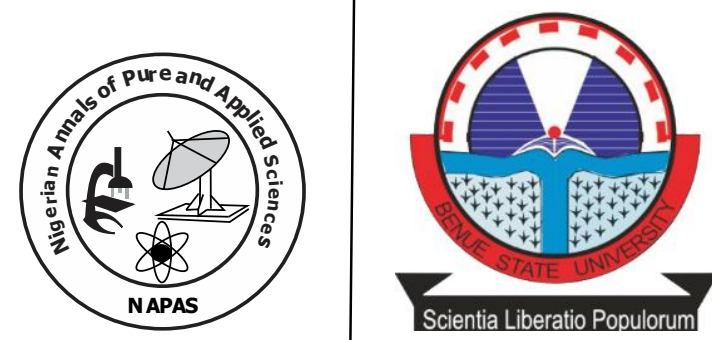

\title{
Antlblogram of the predominant bacterial contaminants of Nigerian currency notes in circulation In Ogun State, Nigerla.
}

\author{
Akpotu Mark Ovuakporaye* and Kehinde Adetola Funmileso \\ Department of Pharmaceutical Microbiology, \\ Faculty of Pharmacy, Olabisi Onabanjo, \\ University, Sagamu Campus, Ogun State, Nigeria. \\ Corresponding author:markakpotu@yahoo.com
}

doi: https//doi.org/10.46912/napas.241

\begin{abstract}
Currency notes can act as a vehicle for the transmission of pathogenic organisms. This study was carried out to determine the antibiotic susceptibility patterns of the predominant bacterial contaminants of Nigerian currency notes in circulation in parts of Ogun State. A total of 240 naira notes of 8 different denominations were collected from various persons into sterile polythene bags, transferred into universal bottles containing $10 \mathrm{~mL}$ of sterile buffered peptone water. The notes were removed; the resulting solution incubated overnight and the overnight solution inoculated onto Blood agar, Mannitol salt agar, Eosin Methylene Blue agar and MacConkey agar plates and incubated at $37^{\circ} \mathrm{C}$ for 24 hours. The isolates were then identified by Gram reactions and Biochemical tests and their susceptibility profiles against 8 commonly used antibiotics were determined. A total of 95 out of the 240 samples showed bacterial contamination and the prevalent isolates include: Escherichia coli 31 (32.6\%), Salmonella typhi 26 (27.4\%), Staphylococcus aureus 20 (21.1\%) and Bacillus subtilis 18 (18.9\%) respectively. There was no bacteria growth on the control samples. $52.3 \%$ of the isolates were resistant strains. EC 1 isolate showed the highest susceptibility with an inhibitory zone diameter (IZD) of $25 \mathrm{~mm}$ against ciprofloxacin while on the whole, $26.6 \%$ of the isolates were susceptible to all the antibiotics evaluated with $20.9 \%$ showing intermediate susceptibility. This study showed that most of the circulating currency notes harbored one or more bacteria, especially the resistant strains which could pose a severe public health challenge.
\end{abstract}

Key words: Antibiogram, Bacteria contaminants, Currency notes, Ogun State. 


\section{Introduction}

Naira, the official legal tender in Nigeria, became operational in 1973, replacing the Nigerian pounds and shillings. Over the years it has gone through a number of improvements to enhance its aesthetics, security as well as durability. Apart from Nigeria, the paper currency is equally used in the rest of the world (Sadawarte et al, 2014). The currency notes currently available for business transactions are: $\$ 5$, $\$ 10$, $\$ 20, \$ 50, \# 100, \$ 200, \$ 500$ and $\$ 1000$. The first four currency denominations are made with polymers and the others are made of papers. These Nigerian currency notes are passed from hand to hand by different categories of individuals whose personal hygiene may be poor, thereby contaminating the notes with pathogenic organisms (Borah et al, 2012; Umeh et al, 2007). Thus, currency notes serve as a vehicle for the further transmission of these disease-causing agents, thereby constituting serious public health concerns (Kawo et al, 2009; Charnock, 2007; Xu et al, 2005). Earlier studies report that the lower denominations of the naira notes tend to harbor more of the pathogens than the higher ones (Barua et al, 2019; Khalil et al, 2014). It has also been said that the paper currency is impregnated with disinfectants of high potency to inhibit the colonization of these currency notes by pathogenic organisms, notwithstanding some disease-causing agents have been isolated from these notes in a number of countries (Hanash et al, 2015; Ahmed et al, 2010; Taro, 2005; Goktas and Oktay, 1992). These pathogenic agents include Staphylococcus aureus, Enterococci sp, Vibrio cholera, Pseudomonas aeruginosa, Shigella sp, Salmonella sp, Mycobacterium tuberculosis, Escherichia coli, Klebsiella sp among others (Hanash et al, 2015; Moosavy et al, 2013). Fungi are also one of the important groups of microorganisms isolated from the Nigerian currency notes: Penicillium sp, Aspergillus fumigatus, Rhizopus sp (Shahram et al, 2009; Barro et al, 2006). These isolates from the currency notes have been shown to carry antibiotic resistant strains; further compounding public health concerns (Firoozeh et al, 2017).

There is insufficient data on the probable microbial contaminants of Nigerian currency notes in Ogun Central and Ogun East Senatorial districts. This research therefore seeks to investigate the prevalent bacterial contaminants in Nigerian currency notes in circulation in the study area as well as to determine the antibiogram of these bacterial contaminants.

\section{Materials and Methods Study Area}

This study was carried out in selected Local Government Areas (LGAs) in Ogun central senatorial district (Abeokuta North, Abeokuta South and Odeda) and some LGAs in Ogun East senatorial district (Ijebu Ode, Ikenne and Sagamu) of Ogun State in Nigeria. The climate in both districts is tropical with rainfall experienced in most months of the year and short dry season. Precipitation is about $77.6^{\prime \prime}$ per annum and average temperature of $26.1{ }^{0} \mathrm{C}(1970 \mathrm{~mm})$ (Climate-Data.org. Retrieved $10^{\text {th }}$ June 2021). The inhabitants of these districts are predominantly farmers, traders, artisans and Civil Servants.

\section{Sample collection}

A total of 240 samples of Naira notes comprising 30 pieces each of the Naira denominations: $\$ 5, \# 10, \$ 20, \$ 50, \# 100, \$ 200$, $\$ 500$ and $\$ 1000$ were randomly collected from butchers, street beggars, filling station attendants, civil servants, water vendors and students into appropriately labeled sterile polythene bags between June and August, 2018 and transported to the Pharmaceutical Microbiology Laboratory of Olabisi Onabanjo University. Currency notes in mint condition, not yet in circulation, freshly obtained from the Central Bank of Nigeria (CBN) were used as control samples.

\section{Bacterial Isolation}

The naira notes were individually transferred from the polythene bags using sterile forceps under aseptic conditions into appropriately labeled individual universal bottles containing $10 \mathrm{~mL}$ of sterile buffered peptone water. The universal bottles were shaken vigorously for 1 minute so as to dislodge substantial microbes on the surface of the paper currency. The paper notes were then removed and the resulting solution was incubated at $37{ }^{\circ} \mathrm{C}$ for 24 hours. This incubated sample was then inoculated onto Blood agar (BA), MacConkey agar (MCA), Mannitol salt agar (MSA) and Eosin Methylene blue agar (EMB) plates, and incubated for 24 hours at $37^{\circ} \mathrm{C}$. The control samples were similarly treated. 


\section{Identification of Isolates}

The discreet colonies obtained were grouped into Gram positive and Gram negative bacteria by Gram staining reactions following the method of Okore with a little modification (Okore, 2008). Briefly, a smear of the bacterial cells were prepared on clean glass slide and thereafter heat fixed. This smear was then flooded with a basic dye called Gentian violet (primary dye) and then allowed to stand for 60 seconds. The dye was washed off gently with water and an aqueous solution of iodine was applied for 60 seconds, which acts as a mordant to help bind the primary dye to the cells. The stained cells were then washed with $95 \%$ ethanol for 30 seconds and rinsed with water for few seconds. The next stage was the application of Safranin, the counter stain, for about 60 seconds and rinsed with water for 5 seconds. Finally, it was blotted and examined under oil immersion.

Further authentication on the bacterial cells was done by carrying out Biochemical tests such as the catalase test, coagulase test, indole test, citrate utilization test, oxidase test according to Esimone et al, (2010); Willey et al, (2008).

1. Catalase test: This test was intended to differentiate Streptococcus (-) from Staphylococcus (+) as well as Bacillus (+) from Clostridium (-). A discreet colony was transferred into a clean glass slide and 1 drop of $3 \% \mathrm{H}_{2} \mathrm{O}_{2}$ (Hydrogen peroxide) was added into it. The presence of bubbles due to the conversion of $\mathrm{H}_{2} \mathrm{O}_{2}$ to $\mathrm{H}_{2} \mathrm{O}$ and $\mathrm{O}_{2}$ indicates the presence of catalase.

2. Coagulase test: This test was important for this study in order to differentiate Staphylococcus aureus (+) from Staphylococcus epidermidis (-). Two drops of normal saline was dispensed onto a clean glass slide. The two drops of normal saline was then emulsified with the bacterial using inoculating loop. Next, a drop of plasma was added to the smear on the glass slide and rocked gently for about 15 seconds. A positive test would show clumping within 10-15 seconds.

3. Indole test: This test was intended to separate Escherichia coli (MR+, VP-, indole + ) from Enterobacter (MR-, VP+, indole -) and Klebsiella pneumonia (MR-, $\mathrm{VP}+$, indole-). Pure bacterial culture was inoculated into a tube containing peptone water and incubated for 24 hours.
Thereafter, 5 drops of Kovac's reagent was added to the culture. A positive result is inferred by a red color in the surface layer of the culture and a negative result appears yellow.

4. Oxidase test: This test helps to distinguish Neisseria and Moraxella spp. (+) from Acinetobacter (-) and, enterics (all -) from pseudomonads (+). Briefly, 2 drops of $1 \%$ oxidase reagents was added on a piece of filter paper on a clean glass slide. With the aid of inoculating loop, the bacterial cell was aseptically transferred onto the filter paper on the glass slide and emulsified with the reagent. A positive reaction turns the bacteria violet and negative reaction remains colorless within 30 seconds.

5. Citrate utilization test: This test was necessary in order to identify many of the enteric bacteria such as: Klebsiella $(+)$, Enterobacter (+), Salmonella (+), Escherichia (-), Edwardsiella (-). Briefly, discreet bacterial colony of not more than 24 hours old was inoculated onto Simmons citrate agar and allowed to incubate at $37{ }^{\circ} \mathrm{C}$ for 7 days. Growth on the medium and sometimes with color change from green to blue is positive for citrate utilization and no growth signifies negative citrate utilization.

\section{Antimicrobial Susceptibility Testing}

This was carried out using the procedure according to Ngwai and coworkers with a little modification (Ngwai et al, 2010). Briefly, discreet bacterial colonies from nutrient agar slants were aseptically transferred into tubes containing Mueller Hinton Broth (MHB) and incubated at 37 ${ }^{0} \mathrm{C}$ for 24 hours. The bacterial suspensions were then standardized to $0.5 \mathrm{McF}$ arland's standard and the entire surface of Mueller Hinton agar (MHA) plates were streaked with the suspension and then allowed to dry. The multiple discs (Rapid lab) containing ceftriaxone $(30 \mu \mathrm{g})$, cefuroxime $(30 \mu \mathrm{g})$, gentamicin $(10 \mu \mathrm{g})$, ampicillin $(10 \mu \mathrm{g})$, ofloxacin $(5 \mu \mathrm{g})$, augmentin $(30 \mu \mathrm{g})$, nitrofurantoin $(300 \mu \mathrm{g})$ and ciprofloxacin $(5 \mu \mathrm{g})$ were placed aseptically onto the MHA plates, allowed 10 minutes for pre-diffusion and then incubated in inverted position at $37{ }^{\circ} \mathrm{C}$ for 24 hours. The inhibitory Zone diameters were measured in millimeter $(\mathrm{mm})$ and then classified as Susceptible (S), Intermediate (I) and Resistant (R) based on the interpretative criteria provided 
by the Clinical and Laboratory Standards Institute (CLSI, 2017).

\section{Statistical Analysis}

The generated data were analyzed using the Statistical Package for Social Sciences (SPSS) version 22.0 by one way analysis of variance (ANOVA) and significance taken at $\mathrm{p}<0.05$

\section{Results}

Table 1: Bacterial Isolates from the Different Currency Notes

Table 1: Shows the number of bacteria contaminants isolated from each of the denomination of the Naira notes evaluated.

\begin{tabular}{|c|c|c|c|c|c|c|c|c|}
\hline \multirow[t]{2}{*}{ Isolates } & \multicolumn{6}{|c|}{ Denominations ( $\mathbb{N}$ ) } & \multirow[b]{2}{*}{500} & \multirow[b]{2}{*}{1000} \\
\hline & 5 & 10 & 20 & 50 & 100 & 200 & & \\
\hline Escherichia coli & 2 & 2 & 1 & 3 & 5 & 6 & 5 & 7 \\
\hline Staphylococcus aureus & 1 & 0 & 0 & 3 & 4 & 5 & 3 & 4 \\
\hline Salmonella typhi & 1 & 3 & 2 & 1 & 4 & 5 & 5 & 5 \\
\hline Bacillus sp. & 0 & 2 & 0 & 1 & 4 & 3 & 4 & 4 \\
\hline
\end{tabular}

Table 2: Isolation Rate for the Isolates Obtained

\begin{tabular}{lll}
\hline Notes Sampled $(\mathbf{n})$ & Total Isolates $(\mathbf{t})$ & Isolation Rate $(\mathbf{t} / \mathbf{n} * \mathbf{1 0 0})$ \\
\hline 240 & 95 & 39.6 \\
\hline
\end{tabular}

Table 2 shows the isolation rate of the bacterial contaminants isolated from the currency note. We can observe from the table the relatively low isolation rate of $39.6 \%$.

Table 3: Biochemical Tests and Gram Staining Reaction Outcomes for the Isolates

\begin{tabular}{|c|c|c|c|c|c|}
\hline Gram staining & Catalase test & Coagulase test & Indole test & Oxidase test & Citrate utilization test \\
\hline \multicolumn{6}{|c|}{ Escherichia coli } \\
\hline - & - & - & + & - & - \\
\hline- & - & - & + & - & - \\
\hline- & - & - & + & - & - \\
\hline- & - & - & + & - & - \\
\hline- & - & - & + & - & - \\
\hline- & - & - & + & - & - \\
\hline- & - & - & + & - & - \\
\hline- & - & - & + & - & - \\
\hline- & - & - & + & - & - \\
\hline- & - & - & + & - & - \\
\hline- & - & - & + & - & - \\
\hline- & - & - & + & - & - \\
\hline- & - & - & + & - & - \\
\hline- & - & - & + & - & - \\
\hline- & - & - & + & - & - \\
\hline- & - & - & + & - & - \\
\hline- & - & - & + & - & - \\
\hline- & - & - & + & - & - \\
\hline- & - & - & + & - & - \\
\hline- & - & - & + & - & - \\
\hline- & - & - & + & - & - \\
\hline- & - & - & + & - & - \\
\hline- & - & - & + & - & - \\
\hline- & - & - & + & - & - \\
\hline- & - & - & + & - & - \\
\hline- & - & - & + & - & - \\
\hline- & - & - & + & - & - \\
\hline- & - & - & + & - & - \\
\hline- & - & - & + & - & - \\
\hline- & - & - & + & - & - \\
\hline- & - & - & + & - & - \\
\hline \multicolumn{6}{|c|}{ Staphylococcus aureus } \\
\hline+ & + & + & - & - & - \\
\hline+ & + & + & - & - & - \\
\hline+ & + & + & - & - & - \\
\hline+ & + & + & - & - & - \\
\hline+ & + & + & - & - & - \\
\hline+ & + & + & - & - & - \\
\hline+ & + & + & - & - & - \\
\hline+ & + & + & - & - & - \\
\hline+ & + & + & - & - & - \\
\hline
\end{tabular}




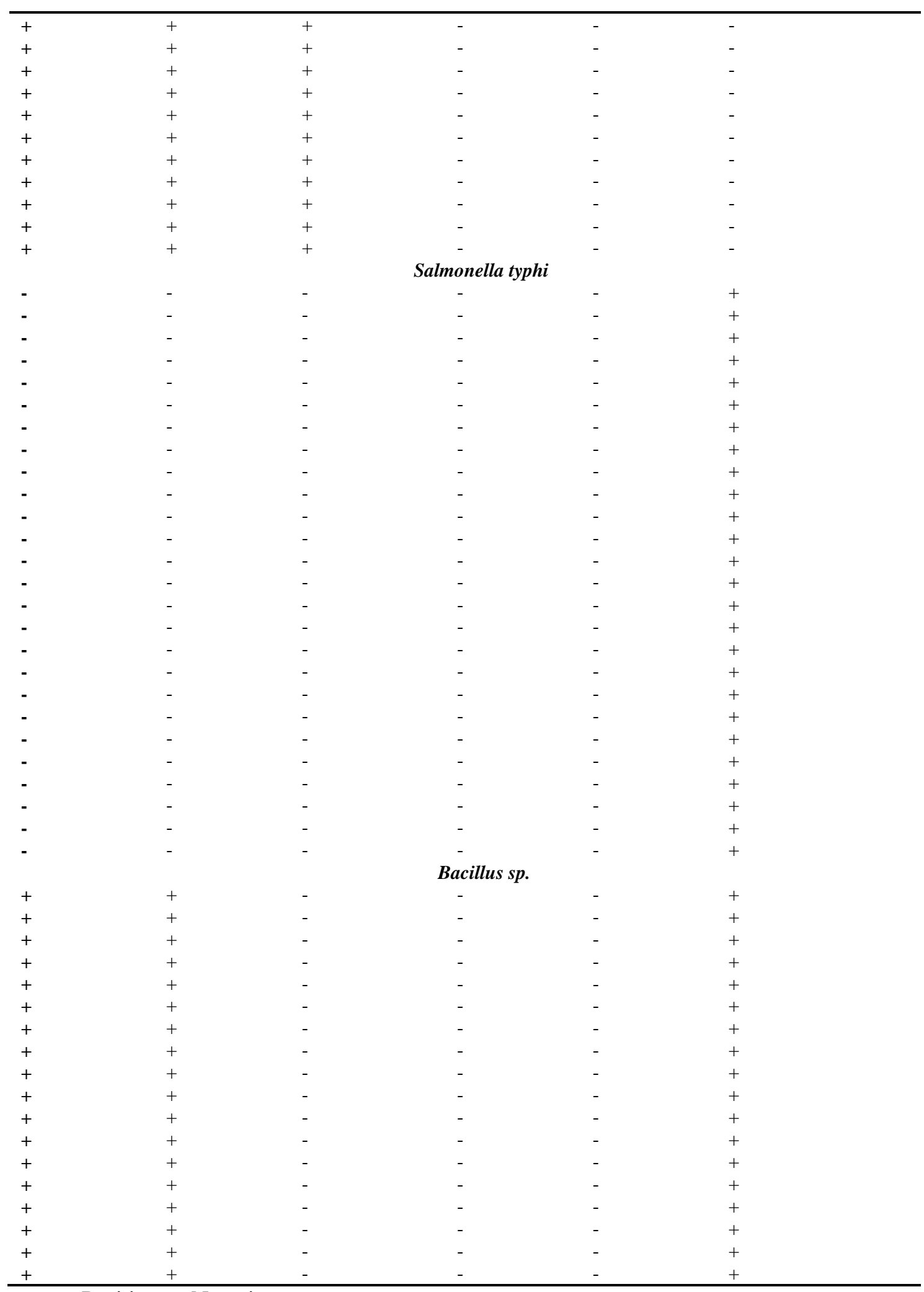

Key: +: Positive, -: Negative

This table shows the staining reaction for the isolates, that is, whether Gram positive (Staphylococcus aureus, Bacillus sp.) or Gram negative (Escherichia coli, Salmonella typhi) and their biochemical reaction outcome to further narrow down on the genus and/ or species of the isolates. 
Table 4: Antibiogram of the Isolates

\begin{tabular}{|c|c|c|c|c|c|c|c|c|c|c|c|c|c|c|c|c|c|c|c|c|c|c|c|}
\hline \multicolumn{24}{|c|}{ Inhibitory Zone diameters (mm) } \\
\hline \multicolumn{3}{|c|}{$\overline{C A Z}$} & \multicolumn{3}{|c|}{ CRX } & \multicolumn{3}{|c|}{ GEN } & & $\overline{\mathbf{M}}$ & & & $\overline{\text { OFI }}$ & & & $\overline{\mathbf{A U G}}$ & & & NIT & & & $\overline{\mathrm{CPR}}$ & \\
\hline $\mathbf{S}$ & $\mathbf{I}$ & $\mathbf{R}$ & $\mathbf{S}$ & $\mathbf{I}$ & $\mathbf{R}$ & $\mathbf{S}$ & $\mathbf{I}$ & $\mathbf{R}$ & $\mathbf{S}$ & I & $\mathbf{R}$ & $\mathbf{S}$ & I & $\mathbf{R}$ & $\mathbf{S}$ & $\mathbf{I}$ & $\mathbf{R}$ & $\mathbf{S}$ & $\mathbf{I}$ & $\mathbf{R}$ & $\mathbf{S}$ & $\mathbf{I}$ & $\mathbf{R}$ \\
\hline & & 0 & & & 0 & 20 & & & & $\begin{array}{r}\text { che } \\
15\end{array}$ & chi & $\begin{array}{l}\boldsymbol{l i} \\
23\end{array}$ & & & & & 10 & & & 10 & 25 & & \\
\hline & & 8 & & & 0 & 15 & & & & & 0 & & 15 & & & & 0 & & & 0 & & 20 & \\
\hline & & 0 & & & 0 & 20 & & & & & 0 & 23 & & & & & 0 & & & 0 & 24 & & \\
\hline & & 10 & & & 8 & 19 & & & & 14 & & 20 & & & 18 & & & 20 & & & & 19 & \\
\hline & & 0 & & & 0 & 15 & & & & 15 & & & & 0 & & & 10 & 19 & & & & 20 & \\
\hline & & 13 & & 17 & & 20 & & & $1^{\prime}$ & & & 19 & & & 18 & & & 22 & & & 21 & & \\
\hline & & 7 & & & 0 & & & 0 & & & 0 & 17 & & & 20 & & & 15 & & & & 17 & \\
\hline & & 10 & 19 & & & & & 10 & 2 & & & 19 & & & & 16 & & 20 & & & & 20 & \\
\hline & & 15 & & & 0 & 18 & & & & 15 & & 20 & & & 18 & & & 20 & & & 21 & & \\
\hline & & 15 & & & 10 & 20 & & & & 16 & & 19 & & & & & 10 & 21 & & & & 20 & \\
\hline & & 12 & & & 12 & 19 & & & & 15 & & 20 & & & & 16 & & 19 & & & & 19 & \\
\hline & 18 & & & & 12 & 22 & & & 1 & & & 21 & & & & 15 & & 19 & & & 22 & & \\
\hline & & 16 & & 15 & & 19 & & & & & 0 & 19 & & & & & 13 & 19 & & & & 19 & \\
\hline & & 7 & & 16 & & 19 & & & & & 0 & 18 & & & & 14 & & 20 & & & & 20 & \\
\hline & & 10 & & 15 & & 21 & & & & & 0 & 19 & & & & 14 & & 18 & & & 21 & & \\
\hline & & 10 & & & 13 & 20 & & & & & 12 & 20 & & & 19 & & & 21 & & & & 19 & \\
\hline & & 15 & 20 & & & 20 & & & & 14 & & 21 & & & & & 9 & 21 & & & & 20 & \\
\hline & & 10 & 22 & & & 21 & & & & & 12 & & & 0 & & & 5 & 20 & & & 21 & & \\
\hline & & 17 & 19 & & & 20 & & & 2 & & & & & 6 & & & 0 & 18 & & & & 19 & \\
\hline & & 0 & & 17 & & 19 & & & 18 & & & & & 9 & & & 5 & 19 & & & & 20 & \\
\hline & & 0 & & & 9 & 19 & & & 1 & & & & & 12 & & & 0 & 17 & & & & & 0 \\
\hline & & 9 & & & 10 & 15 & & & & & 5 & 19 & & & & & 0 & & 16 & & & & 5 \\
\hline & 19 & & & & 11 & 19 & & & & & 8 & 21 & & & & & 10 & & 15 & & & & 14 \\
\hline & & 15 & & 15 & & 21 & & & & & 13 & 20 & & & & 14 & & & & 0 & & & 15 \\
\hline & & 12 & & 15 & & 10 & & & & & 9 & & & 5 & & 14 & & & & 9 & & 19 & \\
\hline & & 14 & 18 & & & 19 & & & & 15 & & & & 0 & & & 13 & & & 3 & & 20 & \\
\hline & & 5 & & & 0 & & & 0 & & & 13 & & & 9 & 19 & & & & & 9 & & & 5 \\
\hline & & 9 & & & 7 & 15 & & & & 15 & & & & 6 & 20 & & & & & 6 & & & 0 \\
\hline & & 16 & & & 0 & & & 0 & & & 6 & 19 & & & 21 & & & 19 & & & & & 12 \\
\hline & 19 & & & & 0 & & & 0 & & & 6 & 19 & & & 22 & & & 21 & & & & & 0 \\
\hline & 19 & & 15 & & & 21 & & & & & 8 & 20 & & & 6 & & & 18 & & & & & 5 \\
\hline & & & & & & & & & apl & loc & $c u$ & reu & & & & & & & & & & & \\
\hline & 19 & & 20 & & & & & 10 & & & 0 & 20 & & & & & 10 & & & 0 & & 19 & \\
\hline & 20 & & 18 & & & & & 9 & & & 0 & 19 & & & & & 10 & & & 10 & & 19 & \\
\hline & 18 & & 19 & & & & & 4 & & & 5 & 19 & & & & & 8 & & & 12 & 21 & & \\
\hline & & 17 & 19 & & & & & 12 & & & 13 & 20 & & & & & 3 & & & 13 & 21 & & \\
\hline & 19 & & 20 & & & & 13 & & & & 10 & 20 & & & & & 12 & 19 & & & & 20 & \\
\hline & 20 & & 18 & & & & 13 & & & & 9 & 18 & & & & & 0 & & 15 & & & 20 & \\
\hline & 18 & & 18 & & & 15 & & & & & 13 & 17 & & & & & 9 & 20 & & & & 19 & \\
\hline & 19 & & & 17 & & & & 0 & & & 0 & & 13 & & & & 0 & & & 6 & 21 & & \\
\hline & 20 & & & 15 & & & & 0 & & & 3 & & & 12 & & & 0 & & & 3 & & 20 & \\
\hline & & 17 & & 16 & & & & 0 & & & 13 & & 13 & & & & 0 & & & 0 & & 20 & \\
\hline & & 17 & & & 9 & & & 7 & & & 12 & 19 & & & & & 5 & & & 6 & & 19 & \\
\hline & 19 & & & & 6 & 16 & & & & & 0 & & & 0 & & & 8 & & & 0 & & & 15 \\
\hline & 20 & & 21 & & & & & 9 & & & 11 & & & 3 & & & 9 & & & 2 & & & 14 \\
\hline & 20 & & & & 6 & & & 6 & & & 7 & & & 5 & & & 12 & & & 0 & & & 14 \\
\hline & & 17 & 18 & & & & & 9 & & & 7 & 19 & & & & 15 & & & & 10 & & 18 & \\
\hline & 19 & & 19 & & & 17 & & & & & 5 & 22 & & & & & 12 & 18 & & & & 19 & \\
\hline & 19 & & 20 & & & & 14 & & & & 0 & 20 & & & & & 10 & 19 & & & & 20 & \\
\hline & & 7 & 19 & & & & & 0 & & & 2 & 20 & & & & 15 & & 19 & & & & 19 & \\
\hline & & 15 & 18 & & & & & 3 & & 14 & & & & 12 & & & 13 & 21 & & & & 19 & \\
\hline & & 16 & & 15 & & & & 5 & & & 12 & & & 0 & & 15 & & & 15 & & & 17 & \\
\hline & & & & & & & & & & nor & lla & & & & & & & & & & & & \\
\hline & 19 & & & & 0 & & & 10 & & & 10 & 19 & & & & & 4 & & & 10 & & 20 & \\
\hline & 18 & & & & 0 & 15 & & & & & 0 & 20 & & & & & 6 & & & 10 & & 19 & \\
\hline & 19 & & & & 0 & 17 & & & & & 0 & 17 & & & & & 10 & & & 6 & 21 & & \\
\hline & & 15 & & & 13 & 17 & & & & & 0 & & 15 & & & & 8 & & & 12 & & 19 & \\
\hline & & 0 & & 16 & & 10 & & & & & 0 & & & 0 & & & 2 & & & 12 & & 18 & \\
\hline & & 0 & 19 & & & 19 & & & & & 6 & & & 0 & & & 0 & & & 9 & & 19 & \\
\hline & & 17 & & & 3 & 10 & & & & & 5 & & & 5 & & & 0 & & & 6 & & 20 & \\
\hline & & 17 & & & 9 & & & 12 & & & 3 & 20 & & & & & 0 & & & 5 & & 17 & \\
\hline & 19 & & 19 & & & & & 12 & & & 8 & 19 & & & & & 12 & & & 0 & & 19 & \\
\hline & & 16 & 18 & & & & & 3 & & & 4 & 19 & & & & & 13 & & & 0 & & & 12 \\
\hline & & 17 & 21 & & & & & 3 & & & 0 & 21 & & & & & 11 & & & 7 & & 19 & \\
\hline
\end{tabular}




\begin{tabular}{|c|c|c|c|c|c|c|c|c|c|c|c|c|c|c|c|}
\hline & 15 & & 15 & & 5 & 5 & 17 & & & 9 & & 13 & & 20 & \\
\hline 18 & & 18 & & & 4 & 0 & & 5 & & 7 & 15 & & & & 0 \\
\hline 18 & & & 17 & & 0 & 6 & 18 & & & 10 & 15 & & & & 5 \\
\hline & 9 & & 17 & & 0 & 10 & 19 & & & 3 & & 12 & & 19 & \\
\hline & 9 & 18 & & & 0 & 0 & 19 & & & 0 & & 9 & 21 & & \\
\hline & 8 & & 17 & & 0 & 8 & 20 & & & 0 & & 3 & & 19 & \\
\hline & 5 & 19 & & & 0 & 10 & 21 & & & 4 & & 2 & & 19 & \\
\hline 19 & & 19 & & & 0 & 8 & 19 & & & 5 & & 6 & & 20 & \\
\hline 18 & & & 16 & & 9 & 9 & & & & 5 & & 9 & & & 15 \\
\hline & 4 & & 17 & 16 & & 9 & & & & 6 & & 9 & & & 15 \\
\hline 20 & & & 17 & 19 & & 13 & 20 & & & 9 & & 5 & & 20 & \\
\hline & 12 & & 0 & & 12 & 0 & & 12 & 14 & & & 14 & & 18 & \\
\hline 19 & & & 4 & 18 & & 11 & & 0 & 14 & & & 14 & 21 & & \\
\hline & 8 & & 15 & & 2 & 10 & & 0 & & 6 & & 12 & & 19 & \\
\hline & 16 & & 16 & & & 0 & 21 & & & 3 & & 8 & & 20 & \\
\hline & & & & & & Bacillus & & & & & & & & & \\
\hline & 10 & & 10 & 20 & & 0 & 20 & & & 10 & & 12 & & 19 & \\
\hline & 15 & & 12 & 21 & & 0 & 18 & & & 12 & & 10 & & 20 & \\
\hline & 12 & & 12 & 19 & & 0 & 17 & & 15 & & & 9 & & 20 & \\
\hline & 15 & & 11 & 21 & & 5 & 17 & & 14 & & & 6 & 21 & & \\
\hline & 12 & & 12 & 20 & & 12 & 21 & & & 13 & & 0 & & 18 & \\
\hline 18 & & & 0 & 19 & & 13 & 19 & & & 12 & & 0 & & 18 & \\
\hline & 16 & & 0 & 19 & & 6 & 19 & & & 11 & & 13 & 21 & & \\
\hline & 15 & & 0 & 17 & & 9 & & 0 & & 13 & & 5 & & & 15 \\
\hline & 0 & & 6 & 16 & & 3 & & 6 & 16 & & & 0 & & & 15 \\
\hline & 0 & & 7 & 18 & & 2 & 19 & & 16 & & & 0 & & & 13 \\
\hline & 0 & & 0 & 19 & & 0 & & & & 0 & & 13 & 21 & & \\
\hline & 6 & & 12 & 20 & & 0 & & & & 0 & & 12 & & 19 & \\
\hline & 13 & & 12 & 19 & & 9 & & & & 12 & 15 & & & 17 & \\
\hline & 14 & & 0 & 21 & & 10 & & & & 0 & & 13 & & 20 & \\
\hline & 13 & & 8 & 21 & & 6 & 16 & & & 0 & & 13 & & 20 & \\
\hline & 14 & & 13 & 20 & & 8 & & & & 5 & & 0 & 21 & & \\
\hline & 6 & 11 & & & & 12 & 19 & & & 13 & & 9 & & & 12 \\
\hline & 9 & 10 & & 15 & & 3 & 18 & & & 12 & & 8 & & 19 & \\
\hline
\end{tabular}

Key: CAZ: Ceftaxidine, CRX: Cefuroxime, GEN: Gentamicin, AMP: Ampicillin, OFL: Ofloxacin, AUG: Augmentin, NIT: Nitrofurantoin, CPR: Ciprofloxacin

\section{Discussion}

This study showed the presence of various bacterial contaminants on the naira notes in circulation in our study area. The specific microorganisms identified after subjecting the isolates to Gram staining reaction and further authentication by various biochemical tests (Table 3) include Escherichia coli, Salmonella typhi, Staphylococcus aureus, and Bacillus sp.; the first two being Gram negative bacteria and the last two Gram positive and the Gram negative bacteria isolates seem to be more than the Gram positive (Gram negative 57[60\%] and Gram positive 38 [40 \%]) (Table 3). This agrees with earlier studies that microbes are usually isolated from currency notes (Kawo et al, 2009; Xu et al, 2005). The reasons for this microbial colonization of the currency notes had been giving to be due to the poor handling by various users with different levels of hygienic practices, which over time overwhelms the strong disinfectants impregnated in the currency notes (Hanash et al, 2015; Goktas and Oktay, 1992). It was further observed that $E$. coli constitutes the greatest bioburden among the bacterial isolated (Table 1). This once again is in agreement with earlier researchers (Moosavy et al, 2013; Kawo et al, 2009; Tagoe et al, 2009). The reason for the predominant $E$. coli isolates could be that there was faecal-currency notes communication among a sizeable number of the people whose currency notes were sampled. The study showed a relatively low isolation rate of $39.6 \%$ (Table 2). This is at variance with earlier studies (Kawo et al, 2009; Tagoe et al, 2009). We also observed in this study that the lower denomination currency notes (that is; $\$ 5$, $\$ 10$, $\$ 20$, $\$ 50$ ) were the least colonized by bacterial contaminants compared with the higher denominations (that is; $\$ 100, \$ 200, \$ 500$ and N1000) (Table 1). This again is at variance with earlier researches (Ayandele and Adeniyi, 2011; Umeh et al, 2007). The reason for this could be the nature of the notes made with polymers, which does not allow a firm grip by the bacterial contaminants and the population of the contaminants can easily be reduced by mere accidental water washing of the notes. Its poor moisture retention capacity, which does not encourage the multiplication of the bacterial 
contaminants, could also be given for this observation. The isolates showed varying degree of responses against the eight commonly used antibiotics (Table 4). The EC 1 isolates showed the highest susceptibility with an IZD of $25 \mathrm{~mm}$ against ciprofloxacin (Table 4). $52.3 \%$ of the isolates were resistant strains and this may pose a severe public health concerns.

\section{Conclusion}

This study showed that most of the circulating currency notes in Ogun-East and Ogun-Central Senatorial districts of Ogun State, Nigeria harbor one or more bacteria species, especially the resistant strains which could pose severe public health challenge if measures are not taken to mitigate this trend.

\section{Recommendations}

The populace in these districts sampled and even beyond should be encouraged to maintain proper hygiene and to handle the currency notes with clean hands and in wallets rather than in back pockets or braziers to prevent the colonization of the currency notes by pathogenic organisms. The currency notes made of polymer showed very low bacterial colonization and so the Central Banks are therefore encouraged to use polymers only in the minting of currency notes. The outcome of this research could serve as an interesting template for further studies.

\section{Acknowledgement}

The authors wish to most sincerely thank their institution, Olabisi Onabanjo University, for providing the enabling environment to conduct this research.

\section{References}

Ahmed, M.S.U., Parveen, S., Nasreen, T., Feroza, B (2010). Evaluation of the microbial contamination of Bangladesh paper currency notes (Taka) in circulation. Advances in Biological Research. 4 (5):266-271.

Ayandele, A.A., Adeniyi, S.A (2011). Prevalence and antimicrobial resistance pattern of microorganisms isolated from Naira notes in Ogbomoso North, Nigeria. Journal of Research in Biology. 1(8):587-593.

Barro, N., Bello, A.R., Savadogo, A., Quattara, C.A.T., Iboudo, A.J., Traore, A.S (2006). Hygienic status assessment of dish washing waters, utensils hands and pieces of money from street food processing sites in Ouagadougou. African Journal of Biotechnology. 5(11):1107-1112.

Barua, N., Sabuj, A., Haque, Z.F., Das, M., Hossain, M.T., Saha, S (2019). Survey of bacterial contamination and antibiotic resistance pattern of Bangladeshi paper currency notes in Mymensingh city. African Journal of Microbiology Research. 13 (10):206-213. DOI:

https://doi.org/10.5897/AJMR2018.9032.

Borah, D., Parida, P., Kumar, T (2012). Paper currencies, a potential carrier of pathogenic microorganisms. International Journal of Applied Biology and Pharmaceutical Technology. 3(1):23-25.

Charnock, C (2004). Swabbing of waiting room magazines reveals only low levels of bacterial contamination. British Journal of General Practice. 55(510):37-39.

Climate-Data.org. Climate data for cities worldwide. http://en.climate-data.org. Retrieved $10^{\text {th }}$ June 2021.

CLSI. In: Performance Standards for Antimicrobial disk Susceptibility Testing. Approved Standard (Document M100). 27 $7^{\text {th }}$ Edition. Clinical and Laboratory Standards Institute, Wayne, USA, 2017.

Esimone, C.O., Okoye, E.L., Nzekwe, I.T (2010). Laboratory Handbook of Pharmaceutical Microbiology and Biotechnology. Rex Charles \& Patrick Ltd, Nigeria p 23-25.

Firoozeh, F., Dadgostar, E., Akbari, H., Zibaei, M., Mohammed, S., Sadjjadian, S., Moshtaghi, M.M., Shakib, A (2017). Bacterial contamination of Iranian paper currency and their antibiotic resistance patterns. International Journal of Enteric Pathogens. 5(4):106-110. DOI: https://doi.org/10.15171 /ijep.2017.25.

Goktas, P., Oktay, G (1992). Bacteriological examination of paper money. Mikrobiyol. Bul. 26:344-348.

Hanash, S., Al-baker, S.M., Al-harazi, T., Alkadasi, M., Zahid, A.A (2015). Prevalence of pathogenic bacteria from contaminated Yemeni currency notes in Taiz city. Asian Journal of Research in Pharmaceutical Science. 5(1):8-11. DOI: https://doi.org/10 .5958/2231-5659.2015.00002.8.

Kawo, A.H., Adams, M.S., Abdullahi, B.A., Sanni, N.M (2009). Prevalence and Public health 
implications of the microbial load of abused naira notes. Bayero Journal of Pure and Applied Sciences. 2(1):52-57. DOI: https://doi.org/10.4314/bajopas.v2i1.58458

Khalil, M., Alam, M., Hossain, M., Das, A., Islam, S., Mia, Z (2014). Occurrence of pathogens on paper currency of Bangladesh and their public Health importance. International Journal of Natural and Social Sciences. 1(1):70-74.

Moosavy, M.H., Shavisi, N., Warriner, K., Mostafavi, E (2013). Bacterial contamination of Iranian paper currency. Iranian Journal of Public Health. 42(9):1067-1070.

Ngwai, Y.B., Akpotu, M.O., Obidake, R.E., Sounyo, A.A., Onanuga, A., Origbo, S.O (2010). Antimicrobial Susceptibility of Escherichia coli and other coliforms isolated from the urine of asymptomatic students in Bayelsa State, Nigeria. African Journal of Microbiology Research. 5 (3), 184-191. DOI: https://doi.org/10.5897/AJMR10.006

Okore, V.C (2009). Principles of Pharmaceutical Microbiology. $2^{\text {nd }}$ Edition. Ephrata publishers p10.

Sadawarte, K., Mahobe, H., Saxena, G (2014). Microbial contamination of Indian currency note in Bhophal. Journal of Evolution of Medical and Dental Science. 3(6):1379-1385.
DOI: https://doi.org/10.14260/JEMDS\%2F2 $014 \% 2$ F1995.

Shahram, S.S., Khajehali, E., Zareei, M (2009). Evaluation of the bacterial contamination of the Iranian currency notes. Iranian Journal of Health and Environment. 1(2):81-88.

Tagoe, D., Baidoo, S., Dadzie, I., Ahator, D (2009). A study of Bacterial Contamination of Ghanaian Currency Notes in Circulation. The Internet Journal of Microbiology. 8(2):1-5.

Talaro, KP (2005). In: Foundations in Microbiology. $5^{\text {th }}$ Edition. McGraw-Hill companies Inc. New York, USA, p. 407.

Umeh, E.U., Juluku, J.U., Ichor, T (2007). Microbial contamination of Naira notes in circulation. Research Journal of Environmental Sciences. 1(6): 336-339. DOI: https://dx.doi.org/10 .3923/rjes.2007.336.339.

Willey, J.M., Sherwood, L.M., Woolverton, C.J (2008). Prescott, Harley and Klein's Microbiology. $7^{\text {th }}$ Edition. McGraw-Hill. p869-870.

Xu, J., Moore, J.E., Millar, B.C (2005). Ribosomal DNA (rDNA) identification of the culturable bacteria flora on monetary coinage from 17 currencies. Journal of Environmental Health. 67 (7):51-55. 